\title{
Two unbound granular materials stiffness analysis with staged repeated load CBR test
}

\author{
Abdelaziz SALMI ${ }^{1}$, Lahbib BOUSSHINE ${ }^{1}$, Khaled LAHLOU ${ }^{2}$
}

\author{
1. Structural and material mechanics team (MSM), ENSEM, Hassan II university of Casablanca, Casablanca, \\ Morocco, abdelazziz.salmi@ensem.ac.ma, lbousshine@yahoo.fr \\ 2. Research team in engineering construction (ERIC), EHTP, Casablanca, Morocco, lahlou@ehtp.ac.ma
}

\begin{abstract}
Design methods of flexible pavements in many countries are based on linear elastic behaviour model for Unbound Granular Materials (UGM). In this context, parameters required to characterize an UGM in structural analysis of pavements are Stiffness modulus and Poisson ratio (E and $v)$. This paper presents a study of two UGM stiffness. Finite element simulation of repeated load CBR (RL-CBR) test has allowed to derive equation used in calculation of materials equivalent modulus based on laboratory RL-CBR Outputs. The staged RL-CBR test is used to evaluate material stiffness for different stress states to highlight its influence on UGM stiffness and compare studied materials. Also, this paper shows that even if two materials are different according to the current road authority specifications, they can represent similar stiffness.
\end{abstract}

\section{Keywords: Repeated load CBR, Unbound Granular} Materials, Stiffness modulus, Flexible pavement.

\section{Introduction}

Characterization of UGM in Morocco and many other countries is based on standard tests like gradation, Sand Equivalent, Los Angeles, Micro-Deval and Plasticity Index... etc, which are not enough to evaluate UGM stiffness with efficiency. The French standard [1] specifies some stiffness values for base and sub-base materials according to their intrinsic characteristics when no modulus results from repeated load triaxial test (RLT) exists. However, the RLT test is expensive and can't be used as a routine test in laboratories to provide stiffness modulus in different conditions of use. The Repeated Load CBR (RL-CBR) was introduced for the first time In the Delft University by Molenaar [2] and Validated in the framework of Araya $\mathrm{PhD}$ thesis [3]. This test is similar to the worldwide popular CBR test (Californian Bearing Ration) in road engineering, but cyclic loads are applied. The standard CBR mould or the extra-large one can be used dependent on the tested material gradation. RL-CBR can be used to study mechanical behaviour of unbound or bound materials: resilient behaviour and resistance to permanent deformation. This test is very simple and Its principle is similar to that of the well-known CBR test but repeated load is applied [4]. To transform this test to a triaxial one Araya and all [7] has equipped the mould by strain gauges to measure the mould lateral deformation ant then have access to the lateral stress, then a statistic analysis results makes possible the estimation of: mean vertical stress, lateral stress, Poisson ratio and the equivalent stiffness modulus based linear elastic theory in the triaxial stat of stress.

\section{Materials and Methods}

\section{1 Materials}

The tested materials are an UGM from Bouskoura and another form Tit Mellil noted respectively G-BS and GTM. The standard identification conducted in LPEE laboratories shows that G-BS is a GNA and G-TM is a GNF2 according to Moroccan Catalogue [5]. Fig. 1 summarises Particle Size Distribution (PSD) of G-BS et GTM and show how their curves of passing percentage are beyond the min-max specification curves, respectively, for GNA and GNF2.

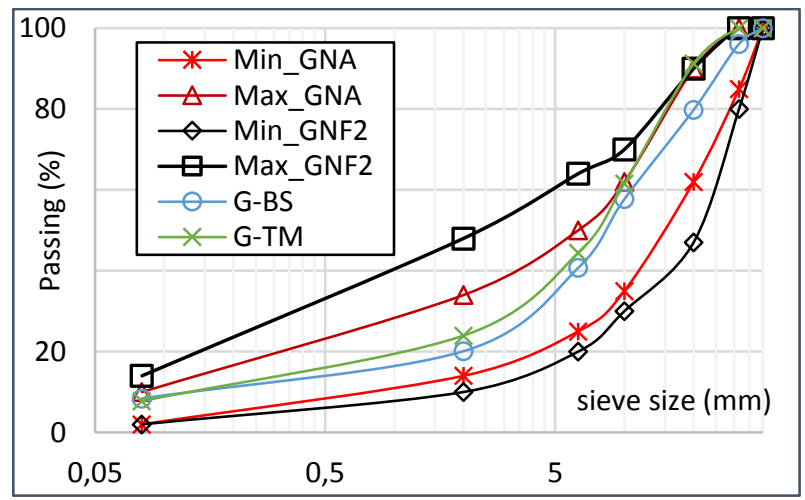

Fig. 1. Particle size distribution of $G-B S$ and $G-T M$ with max and min specification of GNA and GNF2

In addition to PSD, other standard parameters are determined to identify and classify materials according to road authority specifications. Tab. 1 presents characteristics of studied materials and specifications According to [5]. In 
one hand, both materials present a good LA and MDE abrasion index so they respect specification GNA of the most noble UGM in the catalogue, with an upper value of $30 \%$ for LA abrasion index and 20\% for MDE abrasion index. In other hand, Cleanliness for G-TM evaluated by Plasticity Index equal to 8 which is equal to the upper limit for GNF2 in the case of desertic area. However, the Cleanliness G-BS is evaluated by Sand Equivalent index which exceeds the lower limit for a GNA. Specimens are compacted with respect of its Optimum Moisture Content (OMC) determined by Modified Proctor test and a density equal to $98 \%$ of the Optimum Dry Density (ODD). OMC and ODD are summarised in Tab. 2.

Tab. 1. Standard characteristics of G-BS and G-TM

\begin{tabular}{|l|c|c|c|c|}
\cline { 2 - 5 } \multicolumn{1}{c|}{} & \multicolumn{2}{c|}{ Abrasion } & \multicolumn{2}{c|}{ Cleanliness } \\
\cline { 2 - 5 } \multicolumn{1}{c|}{} & $\mathrm{LA}^{1}(\%)$ & $\mathrm{MDE}^{2}(\%)$ & $\mathrm{PI}^{3}(\%)$ & $\mathrm{SE}^{4}(\%)$ \\
\hline GNA & $<30$ & $<20$ & -- & $>30$ \\
\hline GNF2 & $<40$ & $<35$ & $<8$ or $12^{*}$ & -- \\
\hline G-BS & 21 & 10 & -- & 42 \\
\hline G-TM & 26 & 15 & 8 & -- \\
\hline$\bullet$ & $*$ : limit for desertic area (12) other area (8) \\
• & 1: Los Angeles abrasion \\
$\bullet$ & 2: Micro Deval with water \\
$\bullet$ & 3: Plasticity Index \\
$\bullet$ & 4: Sand Equivalent \\
\hline
\end{tabular}

Tab. 2. Compaction references parameters

\begin{tabular}{|l|c|c|}
\cline { 2 - 3 } \multicolumn{1}{c|}{} & OMC (\%) & ODD $\left(\mathrm{t} / \mathrm{m}^{3}\right)$ \\
\hline G-BS & 5.8 & 2.18 \\
\hline G-TM & 4.7 & 2.19 \\
\hline
\end{tabular}

\subsection{Methods}

RL-CBR test used to characterize resilient stiffness UGM is a laboratory test similar to the standard CBR one, but repeated loads are applied. In this study, we have used the extra-large mould adopted by Araya [3] but we have reduced its thickness to $8 \mathrm{~mm}$ instead of 14.5. Eight levels of stress have been applied on each specimen, so we talk about the staged RL-CBR used in the first time by [6]. The objective is to reduce time and necessary specimens' number to study the influence of stress material characteristic. A schematic presentation of the extra-large mould is depicted in Fig. 2.

RL-CBR test consist of applying many load-unload repetitions until permanent penetration of the plunger remains constant or its increase per cycle becomes negligible against reversible penetration. This latter is equal to the difference between the maximum penetration at maximum load and the minimum penetration at minim load. For our two materials 14 load repetitions was sufficient for each stage. Materials stiffness for each stage is evaluated by the Equivalent modulus introduced in the Delft university for the first time with respect to the equation (1).

Model parameters $\mathrm{k}_{\mathrm{i}}$ are determined by nonlinear multiple regression analysis on the results of RL-CBR finite element analysis with respect to mould characteristics especially its thickness (see 3.1).

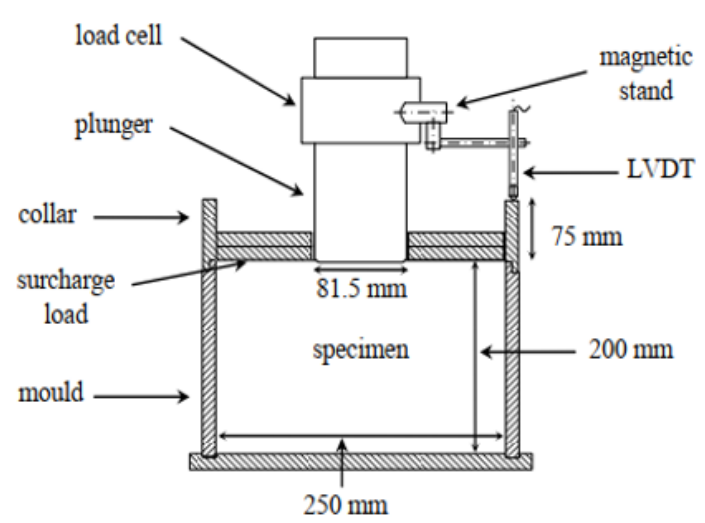

Fig. 2. Schema of the RL-CBR equipment [3]

$$
E_{\text {equ }}=\frac{k_{1}\left(1-v^{k_{2}}\right) \Delta \sigma_{p} a}{\Delta u^{k_{3}}}
$$

avec:

$v \quad:$ Poisson ratio

$\Delta u \quad$ : Reversible plunger penetration ( $\mathrm{mm}$ )

$\Delta \sigma_{p} \quad$ : Mean reversible stress under plunger (MPa)

$a \quad:$ Plunger radius ( $\mathrm{mm})$

$E_{\text {equ }}$ : Equivalent modulus (MPa)

$k_{i} \quad:$ Regression parameters

\section{Results and discussion}

\subsection{Model parameters estimation}

As mentioned above, our mould thickness is different from that of Araya so we have retaken simulations with respect of our mould characteristics. In these simulations many Young moduli (from $25 \mathrm{MPa}$ to $1200 \mathrm{MPa}$ ), Poisson ratio (from 0.25 to 0.45 ) and imposed deflection under the plunger (from $0.2 \mathrm{~mm}$ to $5 \mathrm{~mm}$ ) have been combined. For each combination, Nodal reactions under the plunger are captured and the mean stress under the plunger $\Delta \sigma_{p}$ is calculated. After that, and using the least square method we have obtained parameters values shown in the equation (2) with a correlation coefficient $\mathrm{R}=0.963$ which a high regression quality. Mould material is steel with Young modulus of $210 \mathrm{GPa}$ and a Poisson's ration of 0.2 , the same as Araya mould. RL-CBR is considered as an axisymmetric problem and the finite element model/mesh is reproduced in Fig. 3. Also, examples of vertical and horizontal stress distribution along the symmetric axis of the specimen are shown in Fig. 4 for a Young modulus of $300 \mathrm{MPa}$ and a 1 $\mathrm{mm}$ plunger penetration. The effect of Poisson ratio is also illustrated, it increases both stress along the axis.

$$
E_{e q u}=\frac{1.377\left(1-v^{1.552}\right) \Delta \sigma_{p} a}{\Delta u^{1.056}}
$$

\subsection{Experimental results}

Equivalent modulus versus resilient stress under plunger for two materials G-BS and G-TM is reported in Fig. 5. It shows that stiffness of two materials increases with the stress under plunger which is a demonstration of non-linear behaviour of UGM so modulus used in pavement design are increased from sub-grade to base layer to take into account this materials nonlinearity [1]. 


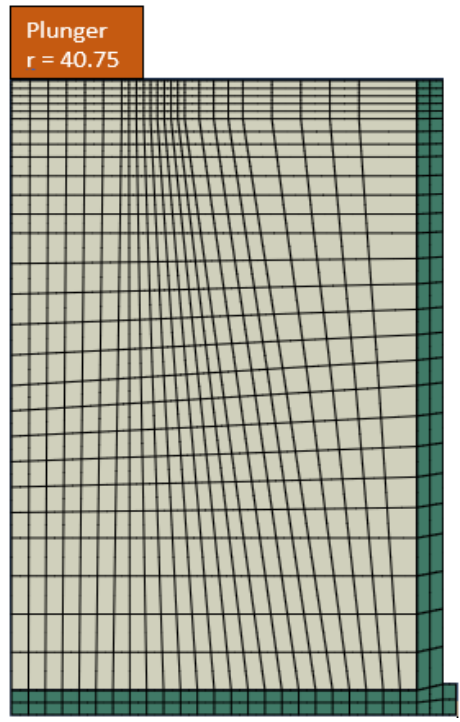

Fig. 3. Axisymmetric model for $R L-C B R$ simulations

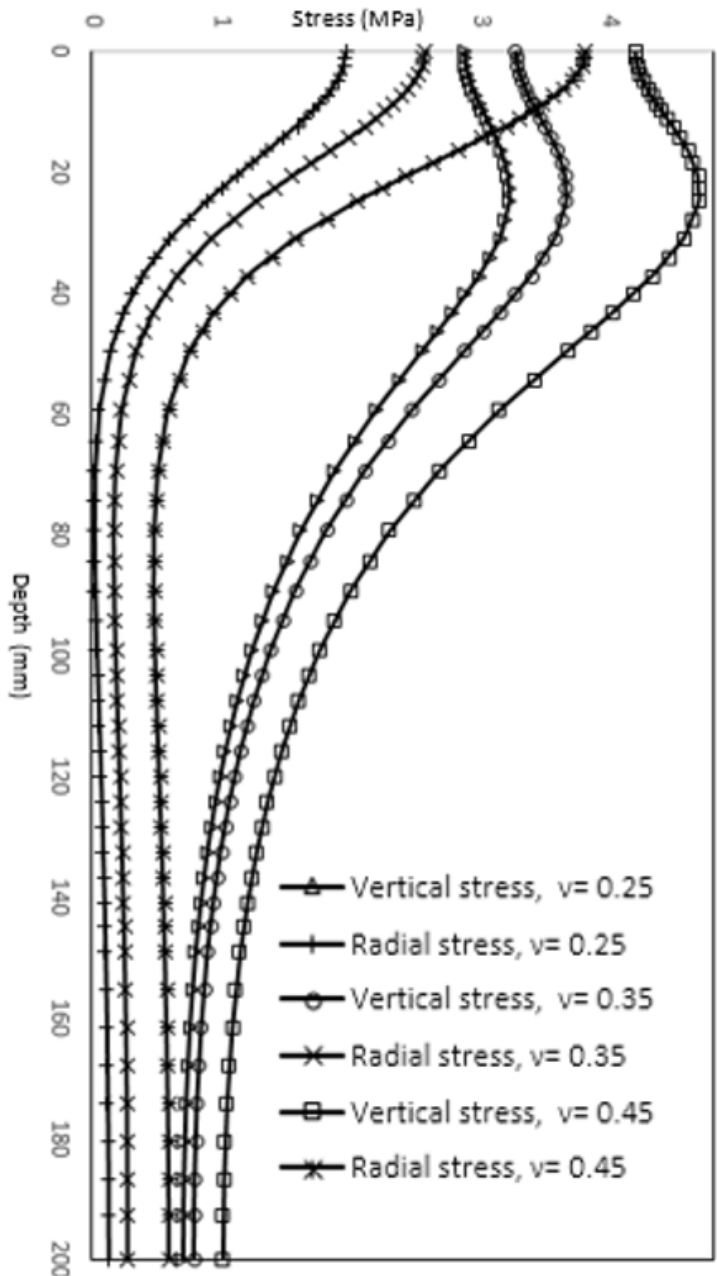

Fig. 4. Vertical and horizontal stress along symmetric axis for $E=300 \mathrm{MPa}$ and $1 \mathrm{~mm}$ plunger penetration

Similar correlation between equivalent modulus and stress has been shown in [7] using mono-stage RL-CBR test, and in [6] using multi-stage RL-CBR test. But the last one did not control the stress level in the first stage which serves to control stress level for other stages: increasing stress by $30 \%$ every stage. The mean equivalent moduli for G-TM and G-BS in tests' conditions are approximately the same and are equal to $360 \mathrm{MPa}$ despite the first material is a GNF2 and the last one is a GNA considered as the most noble UGM in the practical sense of the road authority specifications [5] and other circular notes edited by national road authority.

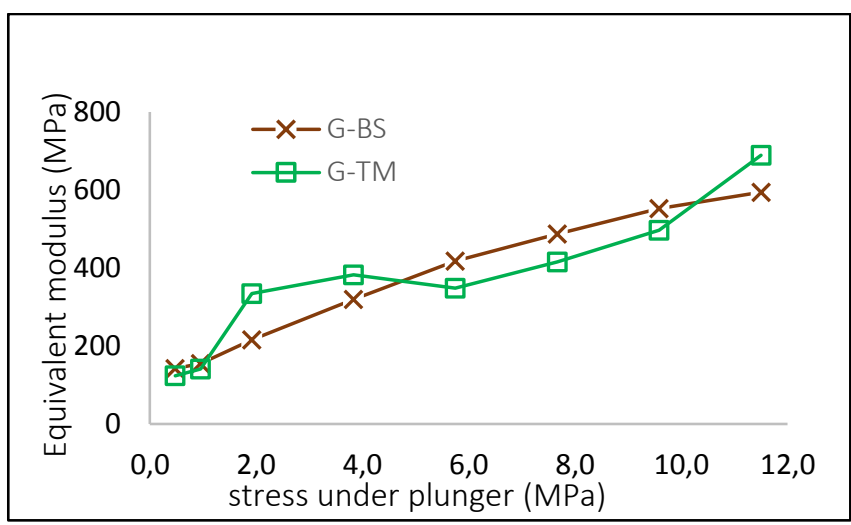

Fig. 5. Equivalent moduli vs reversible stress under plunger

\section{Conclusions and Outlook}

In this paper we have used the staged RL-CBR test to study the stiffness of two UGM. So, we can note that:

- RL-CBR test is an effective tool to study resilient behaviour of UGM,

- UGM have a nonlinear behaviour: Stiffness increase with stress level,

- The mould thickness has an effect on model parameter if equivalent modulus.

In this paper only, the influence of stress state on stiffness is studied for two UGM. And it is important to study the influence of other parameters like moisture, degree of compaction and gradation ...etc. Another outlook is the use RL-CBR test to study the plastic behaviour of UGM.

\section{Références}

[1] AFNOR, NF P98-086- Dimensionnement structurel des chaussées routières-application aux chaussées neuves, 2011.

[2] A. Molenaar, Characterization of Some Tropical Soils for Road Pavements, Journal of the Transportation Research Board, No. 1989, Vol. 2194, 2007.

[3] A. A. Araya, Characterization of Unbound Granular Materials for Pavements, PhD thesis, Delft University of Technology, the Netherlands, 2011.

[4] A. Salmi, K. Lahlou, et L. Bousshine, L'essai CBR à chargement répété: un moyen simple et efficace pour une caractérisation rationnelle des graves non traitées, $10^{\text {ème }}$ congrès national de la route, El Hoceima, Maroc, 2018.

[5] DRCR, Catalogue des structures types de chaussées neuves, Catalogue, Maroc.1995.

[6] H. Haghighi, A. Arulrajah, A. Mohammadinia, et S. Horpibulsuk, A new approach for determining resilient moduli of marginal pavement base materials using the staged repeated load CBR test method, Road Materials and Pavement Design, p. 1-20, juill. 2017.

[7] A. Araya, A. Molenaar, L. Houben, Characterization of unbound granular materials using repeated load CBR and triaxial testing, Geotechnical Special Publication, 2010, p. 355-363.

\section{Acknowledgement:}

* The first author would like to thank Hassan II academy of sciences and technics for its financial support.

* thanks to Pr. Mounia Farah for her review of the paper manuscript. 